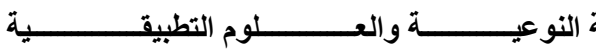

ية للتربيـ

لـة العلم

The Scientific Journal of Specific Education and Applied Sciences

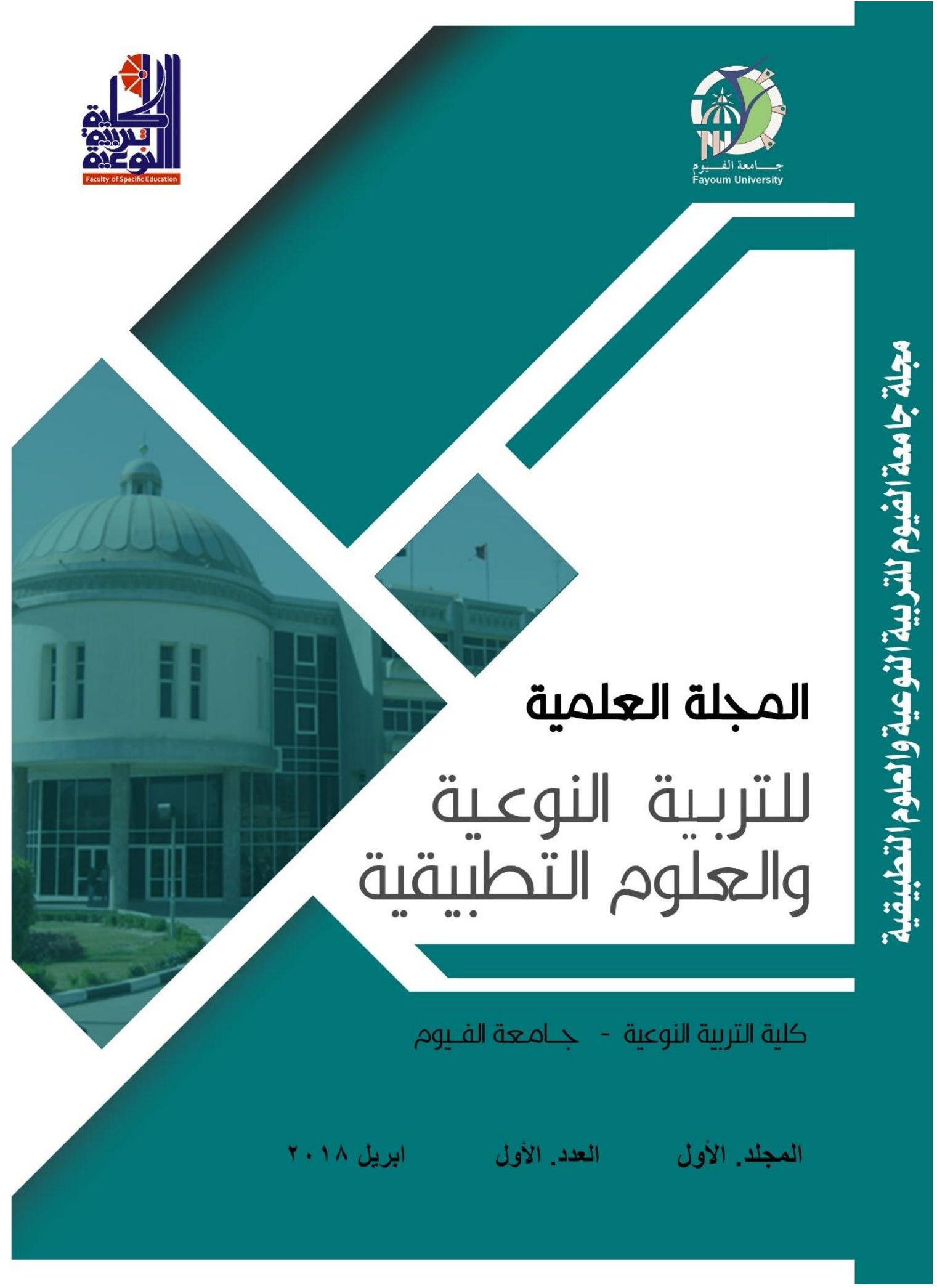




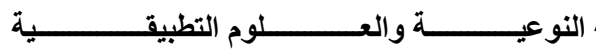
型

\section{The effects of sage (Salvia officinalis) supplementations on the health stats of diabetic animal models: gut microbiota in focus}

\section{Nazeha A. Khalil and Naglaa Ali Magd El Sheihk}

Nutrition and Food Sciences Department, Faculty of Home Economics, Menoufia University, Shebin El-Kom, Egypt

Abstract: Gut microbiota and dietary modifications get much more attention worldwide within the recent two decades. Therefore, the present study was carried out to evaluate the effects of dried supplementations of different percentage of sage (1, 2, 4 and $5 \%$ ) on diabetic rats' healthy stats, intestinal microbiota composition and activities. Five diabetic groups of rat were used in this study, in addition to one group used as negative control group (healthy diet). All rats were used for determining body weight gain (BWG), glucose, cholesterol, high density lipoprotein-cholesterol (HDL-c), and low density lipoprotein-cholesterol (LDL-c). Additionally, intestinal microbioma have been measured including Bifidobacteria, Clostridium histolyticum, and Lactobacillus. The presented data illustrated that glucose levels were significantly $(\mathrm{P} \leq 0.05)$ decreased amongst sage treatment diabetic rats comparing to the control (+) group in independence manner for the first three concentrations (1,2 and 4\%). Then group fed 5\% sage was slightly similar to $4 \%$ group. Also, the best colonic microbiota compositions were consequently matched in a dose independence manner with both Bifidobacteria, and Lactobacillus (probiotics species) comparing to Clostridium levels. Finally, cholesterol and LDL-c levels decreased in sage treatment groups comparing to control (+) group. In conclusion, consuming sage plays an important role in improving and showing potential effects on diabetic rat's health including enhancement of glucose, colonic 


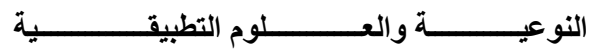

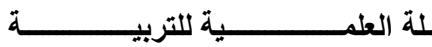

The Scientific Journal of Specific Education and Applied Sciences

microbiota and serum lipids profiles levels. So, sage could be used successfully as a suggestive of prebiotics dietary sources.

Keywords: Prebiotics, probiotics, glucose, serum lipid profile and colonic microbiota

\section{Introduction}

Gut microbiota have shown many connected arms with many disease phenotypes. They can convert the dietary supplementation; mainly the prebiotics into metabolites that provide active molecules and biologically affecting regulatory utilities in the host. The colonic microbiota have more than hundred different bacterial species that dominated by obligate anaerobes particularly Bacteroidaceae, Bifidobacterium, Eubacterium and Peptostreptococcacea. Their cells number are more than the total host cells and form a mass similar to that of mammalian organs (Finegokl et al., 1974; Holdman et al., 1976 and Drasar , 1988; ). Prebiotics well known as non-digestible food ingredients which help the host by stimulating the growth selectively or activity of one or limited numbers of bacteria in the colon and can improved the host health (Roberfroid et al., 2010). In addition, they can restore the colonic microbiota composition with their potential effects showing prevention of gut inflammation. Furthermore, prebiotics will be functional only when it arrives the colon as they will be utilized by a special group of intestinal microbiota such as Bifidobacterium and Lactobacillus and consequently generating metabolites e.g. short-chain fatty acids (SCFAs) such as acetate, propionate and butyrate that could later benefit the host in addition to induce changes within the microbial community composition (Davidson and McDonald, 1998 and Sarbini et al., 2014).

In the recent two decays, prebiotics showed significant benefits effects on the human health status with many diseases such as diabetes. Diabetes mellitus (DM) is a metabolic disorder 


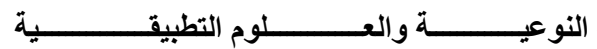
型

distinguished by high levels of blood glucose. It is consists of two types; Type 1 (low levels of insulin depending on the pancreas health status (Rother, 2007); while Type 2 has enough insulin secretion with resistance to be used (Baillie, 2008). So both kids are in needs to be modulated by dietary intervention for either insulin production or resistance. Different dietary intervention studies have been used for long run, for instance, sage leaf extracted and supplemented 3 months to diabetes and hypercholesterol individuals revealed lower levels of fasting glucose, total cholesterol and triglyceride (Kianbakhta and Dabaghian, 2013). Interestingly, one more study showed that sage consumers had improvement in memory with Alzheimer's patients and young and old healthy persons as it enhanced the mood and cognitive performance with inflammation inhibit (Baricevic et al., 2001; Kennedy et al., 2006 and Qnais et al., 2010).

Sage (Salvia officinalis) is the greatest genus of plants as a member of mint family, Lamiaceae, the one of many genera that refers commonly to as sage including many species worldwide (approximately 900 species) which is the common produced herb used in cooking (Walker et al., 2004). Salvia or salviya's name obtained from the Latin word salvere means to be good and healthy. The first author identified the plant name by "Salvia" is Pliny the Elder by the Romans, describing many various species such as the genus Salvia, Salvia officinalis. Sage is relative of the mint family that well known within the Mediterranean area with its values for thousands of years with multiple ranges of uses in cooking and medicine. It also has multitude of bioactive protective compounds that give off a unique, pleasant aroma. For instance, the leaves have tannic acid, oleic acid, estrogenic substances, caffeic and nicotinic acids as well as a powerful class of bio-flavonoids known as flavones that includes apigenin, diosmetin, and luteolin (Abu-Darwish et al., 2013) that shown to 


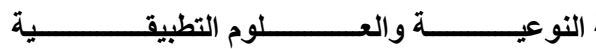
㪿

exert many different pharmacological effects e.g. antiinflammatory, antimicrobial, and anticancer activities (LópezLázaro, 2009 and Byun et al., 2010 ). Thus, eating sage is a fiberrich diet that provides strong flavones, resins, tannic acids, and estrogenic substances. Sage was commonly used in cooking as a patterned and in traditional medicine as anti-inflammatory and anti-cancer in additional to antimicrobial properties. It has been used on the inflammation of the mouth and throat (Dragana, 2005). Either all sage or its extracts, leaves and essential oil are used as dietary supplementations not only with food components consumed in a range of delicious ways (to flavor a meal or to enhance flavor) without adding extra calories or salt but also in cosmetics, and pharmaceutical industries. For instance, saga's essential oils pose different biological activities such as antibacterial, antifungal, and antiviral effects depending on its antioxidant levels (Dragana, 2005). Sage has high contents of antioxidant which can help and protect the body's cells damage by the free radicals leading to impaired immunity and chronic disease. For instance, sage showed positively effects on cognitive skills and neurological disorders. According to our knowledge, there is no data have revealed with colonic microbiota activities of sage. Therefore, the current study aspire an innovative study of sage consumption targeting the composition, functional and biological activities of intestinal microbioma between diabetic rats.

\section{Material and methods \\ Materials}

Sage powder has been acquired from the Agricultural Research Center (ARC), Giza, Egypt. All chemicals in analytical grades and kits were purchased from AlGhomhoriya Company for Trading Drugs, Chemicals and Medical Instruments Cairo, Egypt.

\section{Experimental design}




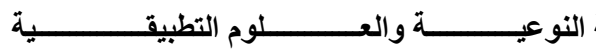
型

Animal models, adult male albino rats, weighting 140+ $10 \mathrm{~g}$, have been purchased from the Experimental Animal Care Centre, National training center, Cairo, Egypt. They all consumed normal diet for up to 3-days, as adaptation time and consumed diets were prepared as described previously by the American Institute of Nutrition (AIN, 1993) recommendation for rodent growth. Afterward, all rats were divided randomly to six groups by six rats each. After that, five groups were diabetes inducers by alloxan (single dose; $150 \mathrm{mg} / \mathrm{kg}$ body weight) as described by Desai and Bhide (1985). Then, in a week time of the injection, fasting blood glucose measured and considers diabetic at $200 \mathrm{mg} / \mathrm{dl}$ or more. Afterwards, rats fed diets supplemented with different sage concentrations (1, 2, 4 and 5\%) in addition to control (-) and control $(+)$. However, one more group fed normal control diet to be used as a negative control and all of them were free to water access for 4 weeks. Before and after running the experimental, the body weight gain (BWG) of each rat was recorded in addition to blood and faecal samples collections at 0,2 and 4 weeks; the end of the experimental. The collected blood samples were kept at room temperature for $30 \mathrm{~min}$ then centrifuged at $3500 \mathrm{rpm}$ for $15 \mathrm{~min}$. Finally; collected serum and faecal were kept at $-80{ }^{\circ} \mathrm{C}$ for further analysis.

\section{Biochemical analysis}

Changes with the body weight gain (BWG, \%) were calculated following Chapman et al., (1959) using the following procedure:

$$
\operatorname{BWG}(\%)=\frac{\text { Final weight }- \text { initial weight }}{\text { Initial weight }} \quad \text { X } 100
$$




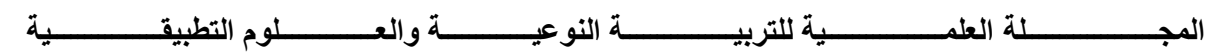

The Scientific Journal of Specific Education and Applied Sciences

Serum glucose evaluation was conducted according to the method of Tinder (1969), serum total CHO was determined by Thomas (1992) and Serum TG using kits according to Fossati and Prencipe, (1982). Also, HDL was established according to method described by Fredewaid (1972) while VLDL was measured in $\mathrm{mg} / \mathrm{dl}$ according to Lee and Nieman (1996) using the following formula: VLDL $(\mathrm{mg} / \mathrm{dl})=\mathrm{TG} / 5$. Finally, LDL was counted according to Lee and Nieman (1996) in $\mathrm{mg} / \mathrm{dl}$ as following: LDL $(\mathrm{mg} / \mathrm{dl})=$ Total $\mathrm{CHO}-(\mathrm{HDL}+\mathrm{VLDL})$

\section{Gut microbiota enumerations}

Colonic microbiota composition (Bifidobacteria, Bif; Clostridium histolyticum, His and Lactobacillus, Lab) were evaluated within the collected faecal samples according to our previous published paper (Khalil et al., 2013). Faecal samples obtained at 0,2 and 4 weeks' time then were diluted by filtered sterilized phosphate-buffered saline (PBS) and fixed at least for 4 $\mathrm{h}\left(4{ }^{\circ} \mathrm{C}\right)$ in $4 \%$ paraformaldehyde (PFA). Then they all left at $4{ }^{\circ} \mathrm{C}$ for $4 \mathrm{~h}$ before being centrifuged for 5 mints at 13,000g. All samples were washed in $1 \mathrm{ml}$ filtered sterilized PBS twice and were resuspended in amount of filtered PBS and ethanol (99\%) equally. Finally, the samples stored at $-20{ }^{\circ} \mathrm{C}$ for at least one hour before processing for further analysis (fluorescence in situ hybridization; FISH). Results were expressed in cells/ml of faecal slurries and logarithmic values were used for further statistical analysis.

\section{Statistical analysis}

Collected data were presented as mean \pm standard deviation (SD) and all the analysis were performed using one-way analysis of variance (ANOVA). Differences among means in triplicates were subsequently tested using Duncan's multiple range as post- 


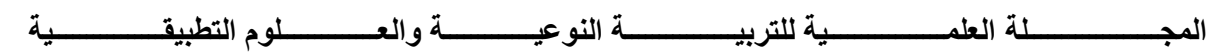

The Scientific Journal of Specific Education and Applied Sciences

hoc test. Data were considered statistically significant differences at $\mathrm{P} \leq 0.05$.

\section{Results and Discussion}

\section{Body weight gain affected by sage consumptions}

Rats body weight values are presented in Table (1) that were affected by dried sage consumptions. It can be seen that body weight in the beginning study within all the used rats ranged between 147 to $152 \mathrm{~g}$ with no significant differences and that reached up to $159 \mathrm{~g}$ at the end of the experimental. The highest increase was maintained at the concentration of $2 \%$ additions of sage (about $7.5 \mathrm{~g}$ ) that is the closest to the negative control group $(13 \mathrm{~g})$ with no significant differences $(\mathrm{p} \leq 0.05)$. However, there is a significant differences were seen between all the groups supplemented with all sage concentrations comparing to the diabetic control group (positive group; $\mathrm{p} \leq 0.05$ ). In addition, the highest sage supplementations (4 and 5\%) were very close affecting the animal's body weight by 7.57 and $7.77 \mathrm{~g}$ respectively.

Table (1): Effect of dried sage consumptions on body weight gain between diabetic rats

\begin{tabular}{c|c|c|c|l}
\hline $\begin{array}{l}\text { \% of Change } \\
\text { from cotnrol } \\
(+)\end{array}$ & $\begin{array}{c}\text { Differences } \\
\text { of body } \\
\text { gain }(\mathrm{g})\end{array}$ & $\begin{array}{c}\text { Final body } \\
\text { weight }(\mathrm{g})\end{array}$ & $\begin{array}{c}\text { Initial body } \\
\text { weight }(\mathrm{g})\end{array}$ & Groups \\
\hline 60.87 & 13.34 & $161.17 \pm 2.02^{\mathrm{a}}$ & $147.83 \pm 2.56^{\mathrm{a}}$ & Control(-) \\
\hline 0 & -7.83 & $143.4 \pm 1.96^{\mathrm{b}}$ & $151.23 \pm 2.92^{\mathrm{a}}$ & Control $(+)$ \\
\hline 47.37 & 5.97 & $158.23 \pm 1.62^{\mathrm{a}}$ & $152.27 \pm 3.90^{\mathrm{a}}$ & Sage 1\% \\
\hline 47.72 & 10.87 & $159.2 \pm 0.72^{\mathrm{a}}$ & $148.33 \pm 1.52^{\mathrm{a}}$ & Sage 2\% \\
\hline 53.73 & 7.57 & $157.9 \pm 2.00^{\mathrm{a}}$ & $150.33 \pm 2.30^{\mathrm{a}}$ & Sage 4\% \\
\hline 53.52 & 7.77 & $158.2 \pm 1.67^{\mathrm{a}}$ & $150.43 \pm 1.11^{\mathrm{a}}$ & Sage 5\% \\
\hline
\end{tabular}




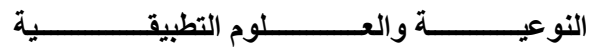

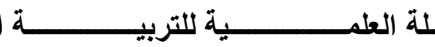

The Scientific Journal of Specific Education and Applied Sciences

Values present mean \pm SD. Means in the same column with different superscript letters were significantly different at $\mathrm{p} \leq 0.05$.

\section{Blood glucose levels affected by sage consumptions between diabetic rats}

Table (2) illustrates the serum glucose levels, which have significant $(\mathrm{p} \leq 0.05)$ changes within the glucose levels between all the rat groups. Serum glucose levels are relatively high within the positive control group $(252.07 \pm 3.31 \mathrm{mg} / \mathrm{dl})$ comparing to all the other groups as it was expected. The negative control group is lowest levels $(98.63 \pm 2.89$ comparing to all the tested groups and the positive control group. however and as mentioned before the highest concentration has been seen with the positive control group (about 250mg/dl). Regarding sage effects, we can see that all sage supplemented concentration has effective reduction for glucose levels. The $1 \%$ is the lowest effect (about $45 \%$ change of control positive group) while 4 and $5 \%$ have the biggest effects, (54\% change of control positive group each of them). It can be notice that such effects are in an independent manner after sage additions between diabetic rats. Such results are in agreements with numerous previous studies that reported sage consumption reduced blood glucose levels with improving the lipid profiles in diabetic's conditions. e.g. researchers in Iran established a study with type II diabetes patients whom have consumed capsule of sage leaf extract shown to have anti-hyperglycemic effects with improving their lipid profile (Kianbakhta and Dabaghian, 2013). 


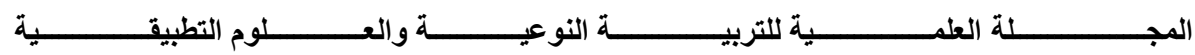

The Scientific Journal of Specific Education and Applied Sciences

Table (2): Effect of dried sage consumptions on blood glucose levels between diabetic rats

Relative \% change of Glucose level (mg/dl) Groups control $(+)$

\begin{tabular}{cll}
\hline 60.87 & $98.63 \pm 2.89^{\mathrm{e}}$ & Control(-); Basal Diet \\
\hline--- & $252.07 \pm 3.31^{\mathrm{a}}$ & Control (+) \\
\hline 45.12 & $138.33 \pm 4.45^{\mathrm{b}}$ & Sage 1\% \\
\hline 49.31 & $127.77 \pm 2.94^{\mathrm{c}}$ & Sage 2\% \\
\hline 53.73 & $116.63 \pm 1.66^{\mathrm{d}}$ & Sage 4\% \\
\hline 53.52 & $117.17 \pm 1.16^{\mathrm{d}}$ & Sage 5\% \\
\hline
\end{tabular}

Data represent mean $\pm \mathrm{SD}$, Means in the same column with different superscript letters were significantly different at $p \leq 0.05$.

\section{Effects of sage consumptions between diabetic rats on lipid} profile

Data presented in Table (3) shown the lipid profile; total cholesterol, triglyceride, high density lipoprotein (HDL), low density lipoprotein (LDL) and very low density lipoprotein (VLDL) after different concentrations of sage consumptions between diabetic rats. For total cholesterol levels, it could be observed that the entire rat groups fed sage with different levels (1, 2,4 and $5 \%$ ) had significant reduction $(\mathrm{p} \leq 0.05 ; 142,124,114$ and $113 \mathrm{mg} / \mathrm{dl}$ respectively) on the serum cholesterol, comparing to the positive diabetic control group "un-treated group" (about $155 \mathrm{mg}$ /dl). Additionally, triglyceride levels were at low level at the control negative group; $69.43 \mathrm{mg} / \mathrm{dl}$ while the control positive group has the major levels of triglyceride $(111.5 \mathrm{mg} / \mathrm{dl})$. Interestingly, all the sage concentrations (1,2, 4 and 5\%) fed animal diabetic groups have a positive decline with the triglyceride levels in an independent manner $(86.5,75.2,73.5$ and $70.2 \mathrm{mg} / \mathrm{dl}$ respectively) which matches the decreases levels with total cholesterol and again with many previous sage supplementation studies either with dried or extracted sage. 


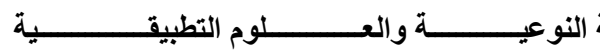

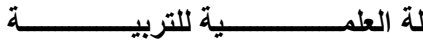

The Scientific Journal of Specific Education and Applied Sciences

Table (3): Effect of dried sage consumptions on lipid profile levels between diabetic rats

\begin{tabular}{cccccl}
\hline $\begin{array}{c}\text { VLDL } \\
(\mathrm{mg} / \mathrm{dl})\end{array}$ & $\begin{array}{c}\text { HDL } \\
(\mathrm{mg} / \mathrm{dl})\end{array}$ & $\begin{array}{c}\text { LDL } \\
(\mathrm{mg} / \mathrm{dl})\end{array}$ & $\begin{array}{c}\text { TG } \\
(\mathrm{mg} / \mathrm{dl})\end{array}$ & $\begin{array}{c}\text { CHO } \\
(\mathrm{mg} / \mathrm{dl})\end{array}$ & $\begin{array}{l}\text { Animal } \\
\text { groups }\end{array}$ \\
\hline $13.89 \pm 0.52^{\mathrm{d}}$ & $48.48 \pm 1.47^{\mathrm{c}}$ & $33.30 \pm 1.25^{\mathrm{c}}$ & $69.43 \pm 2.60^{\mathrm{d}}$ & $95.67 \pm 3.05^{\mathrm{e}}$ & Control(-) \\
\hline $22.30 \pm 0.89^{\mathrm{a}}$ & $33.33 \pm 5.80^{\mathrm{d}}$ & $99.0 \pm 2.52^{\mathrm{a}}$ & $111.50 \pm 4.49^{\mathrm{a}}$ & $154.63 \pm 4.18^{\mathrm{a}}$ & $\begin{array}{l}\text { Control } \\
(+)\end{array}$ \\
\hline $17.31 \pm 0.32^{\mathrm{b}}$ & $76.73 \pm 1.79^{\mathrm{a}}$ & $47.87 \pm 2.01^{\mathrm{b}}$ & $86.53 \pm 1.64^{\mathrm{b}}$ & $141.90 \pm 2.20^{\mathrm{b}}$ & Sage 1\% \\
\hline $15.05 \pm 0.67^{\mathrm{c}}$ & $71.95 \pm 2.81^{\mathrm{a}}$ & $37.13 \pm 1.45^{\mathrm{c}}$ & $75.23 \pm 3.36^{\mathrm{c}}$ & $124.13 \pm 1.68^{\mathrm{c}}$ & Sage 2\% \\
\hline $14.71 \pm 0.25^{\mathrm{cd}}$ & $62.63 \pm 1.69^{\mathrm{b}}$ & $36.67 \pm 1.55^{\mathrm{c}}$ & $73.53 \pm 1.29^{\mathrm{cd}}$ & $114.00 \pm 2.48^{\mathrm{d}}$ & Sage 4\% \\
\hline $14.05 \pm 0.43^{\mathrm{cd}}$ & $63.45 \pm 4.34^{\mathrm{b}}$ & $35.90 \pm 4.47^{\mathrm{c}}$ & $70.27 \pm 2.17^{\mathrm{cd}}$ & $113.40 \pm 2.06^{\mathrm{d}}$ & Sage 5\% \\
\hline
\end{tabular}

Values present mean \pm SD. Means in the same column with different superscript letters were significantly different at $\mathrm{p} \leq 0.05$.

In addition, LDL-c the harmful lipoprotein is higher at the control (+) groups (about $100 \mathrm{mg} / \mathrm{dl}$ ). However, it has the smallest LDL levels $(33 \mathrm{mg} / \mathrm{dl})$ that is significantly different comparing to the control $(+)$ groups $(p \leq 0.05)$. On the other hand, the HDL-c, the good lipoprotein has been found to be at good increased levels at sage additions of 4 and 5\% that were respectively at about 62 and $63 \mathrm{mg} / \mathrm{dl}$. Again VLDL levels showed similar directions to the ones seen with LDL levels but with low amounts (about $14<22<17<15<15<14 \mathrm{mg} / \mathrm{dl}$ corresponding to Control (-), Control $(+), 1,2,4$, and $5 \%$ of supplemented sage respectively).

\section{Effects of sage consumptions between diabetic rats on colonic microbiota profile}

Intestinal bacteria become very important recently worldwide especially after being effective with dietary interactions that have been connected with many diseases. Diabetic patients have shown previously an alteration with colonic microbiota composition and their metabolic end products; activities. Previous studies shown that diabetic model is associated with colonic profile that is lower with probiotics species such as Bifidobacteria and Lactobacillus which are the beneficial bacteria. Such species are in 


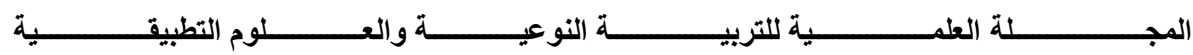

The Scientific Journal of Specific Education and Applied Sciences

need to grow depending on the host dietary consumptions especially the prebiotics that are well known to stimulate probiotics growth thus have potential effects on the host health.

Table (4) illustrates the effects of different concentrated dried sage on colonic microbiota composition fed diabetic rats. It can be seen from table 4 that all sage concentrations are proven to be able to stimulate the growth of probiotics bacterial such as bifidobacteria and Lactobacillus. For instance, the first added percentage; $1 \%$ increased the growth of bifidobacteria and Lactobacillus from $5.47 \times 10^{5}$ and $5.87 \times 10^{5}$ to $6.06 \times 10^{6}$ and $6.14 \times 10^{6}$ cells $/ \mathrm{ml}$ feacal slurry respectively at $5 \%$ fed sage levels at the end of the experimental time. However, sage has been noticed not to be a preferable substrate for the Clostridium histolyticum group that was declined from $6.09 \times 10^{6}$ to about $5.5 \times 10^{5}$ cells $/ \mathrm{ml}$ feacal slurry that was similar at different consumed levels such as $4 \& 5 \%$ after the four weeks experimental. Such data are in agreements with previous prebiotics study with resistance starch that were preferable substrate for the probiotics (Scott et al., 2014). Additionally, sage has revealed as a provider of strong flavones, resins, tannic acids, and estrogenic substances so have been proposed as preventive and therapeutic measures, in order to restore the healthy composition and function of the gut microbiome.

Table (4): Effect of dried sage supplementations on gut microbiota compositions between diabetic rats

\begin{tabular}{|c|c|c|c|c|}
\hline \multicolumn{3}{|c|}{ Bacterial counts ( $\log { }^{10}$ cells /ml feacal slurry) } & \multirow[b]{2}{*}{$\begin{array}{l}\text { Time } \\
\text { (week) }\end{array}$} & \multirow[b]{2}{*}{ Treatments } \\
\hline $\begin{array}{c}\text { Clostridium } \\
\text { histolyticum group }\end{array}$ & Lactobacillus & Bifidobacteria & & \\
\hline $5.45 \times 10^{5} \pm 0.03^{\mathrm{e}}$ & $6.15 \times 10^{6} \pm 0.04^{\mathrm{ab}}$ & $6.01 \times 10^{6} \pm 0.08^{a}$ & 0 & \multirow{3}{*}{$\begin{array}{l}\text { Control(-); } \\
\text { Basal Diet }\end{array}$} \\
\hline $5.41 \times 10^{5} \pm 0.08^{\mathrm{e}}$ & $6.18 \times 10^{6} \pm 0.14^{\mathrm{ab}}$ & $6.05 \times 10^{6} \pm 0.12^{\mathrm{a}}$ & 2 & \\
\hline $5.45 \times 10^{5} \pm 0.06^{\mathrm{e}}$ & $6.26 \times 10^{6} \pm 0.06^{\mathrm{a}}$ & $6.08 \times 10^{6} \pm 0.09^{\mathrm{a}}$ & 4 & \\
\hline $6.17 \times 10^{6} \pm 0.04^{\mathrm{a}}$ & $5.85 \times 10^{5} \pm 0.04^{\mathrm{e}}$ & $5.46 \times 10^{5} \pm 0.02^{\mathrm{c}}$ & 0 & \multirow[t]{2}{*}{ Control (+) } \\
\hline $6.16 \times 10^{6} \pm 0.04^{\mathrm{a}}$ & $5.88 \times 10^{5} \pm 0.05^{\mathrm{e}}$ & $5.49 \times 10^{5} \pm 0.04^{\mathrm{c}}$ & 2 & \\
\hline
\end{tabular}




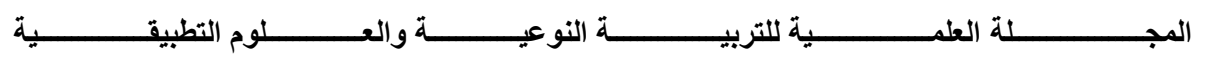

The Scientific Journal of Specific Education and Applied Sciences

\begin{tabular}{|c|c|c|c|c|}
\hline $6.12 \times 10^{6} \pm 0.02^{\mathrm{a}}$ & $5.92 \times 10^{5} \pm 0.07^{\mathrm{de}}$ & $5.46 \times 10^{5} \pm 0.04^{\mathrm{c}}$ & 4 & \multirow{4}{*}{ Sage $1 \%$} \\
\hline $6.12 \times 10^{6} \pm 0.03^{a}$ & $5.89 \times 10^{5} \pm 0.03^{\mathrm{de}}$ & $5.46 \times 10^{5} \pm 0.01^{\mathrm{c}}$ & 0 & \\
\hline $6.15 \times 10^{6} \pm 0.03^{a}$ & $5.83 \times 10^{5} \pm 0.04^{\mathrm{e}}$ & $5.46 \times 10^{5} \pm 0.04^{c}$ & 2 & \\
\hline $6.09 \times 10^{6} \pm 0.06^{\mathrm{a}}$ & $5.87 \times 10^{5} \pm 0.04^{\mathrm{e}}$ & $5.47 \times 10^{5} \pm 0.04^{\mathrm{c}}$ & 4 & \\
\hline $6.07 \times 10^{6} \pm 0.06^{\mathrm{a}}$ & $5.91 \times 10^{5} \pm 0.08^{\mathrm{de}}$ & $5.75 \times 10^{5} \pm 0.07^{\mathrm{c}}$ & 0 & \multirow[t]{3}{*}{ Sage $2 \%$} \\
\hline $5.94 \times 10^{6} \pm 0.05^{b}$ & $6.02 \times 10^{6} \pm 0.03^{\mathrm{cd}}$ & $5.79 \times 10^{5} \pm 0.07^{b}$ & 2 & \\
\hline $5.80 \times 10^{6} \pm 0.07^{\mathrm{c}}$ & $6.06 \times 10^{6} \pm 0.07^{b c}$ & $5.80 \times 10^{5} \pm 0.02^{b}$ & 4 & \\
\hline $6.11 \times 10^{6} \pm 0.01^{\mathrm{a}}$ & $5.92 \times 10^{5} \pm 0.04^{\mathrm{de}}$ & $5.97 \times 10^{5} \pm 0.03^{c}$ & 0 & \multirow[t]{3}{*}{ Sage $4 \%$} \\
\hline $5.74 \times 10^{5} \pm 0.08^{c}$ & $6.15 \times 10^{6} \pm 0.09^{\mathrm{ab}}$ & $5.98 \times 10^{5} \pm 0.01^{\mathrm{a}}$ & 2 & \\
\hline $5.52 \times 10^{5} \pm 0.09^{\mathrm{de}}$ & $6.17 \times 10^{6} \pm 0.05^{\mathrm{ab}}$ & $6.06 \times 10^{6} \pm 0.03^{a}$ & 4 & \\
\hline $6.10 \times 10^{6} \pm 0.02^{a}$ & $5.90 \times 10^{5} \pm 0.10^{\mathrm{de}}$ & $5.97 \times 10^{5} \pm 0.01^{\mathrm{c}}$ & 0 & \multirow[t]{3}{*}{ Sage $5 \%$} \\
\hline $5.59 \times 10^{5} \pm 0.04^{\mathrm{d}}$ & $6.11 \times 10^{6} \pm 0.09^{b c}$ & $6.03 \times 10^{6} \pm 0.01^{\mathrm{a}}$ & 2 & \\
\hline $5.51 \times 10^{5} \pm 0.05^{\mathrm{de}}$ & $6.14 \times 10^{6} \pm 0.05^{\mathrm{abc}}$ & $6.06 \times 10^{6} \pm 0.05^{\mathrm{a}}$ & 4 & \\
\hline
\end{tabular}

Data prove mean \pm SD.. Means in the same column with different superscript letters were significantly different at $\mathrm{p} \leq 0.05$.

The 4 and $5 \%$ of sage additions have shown the best effects on the colonic microbiota compositions and both of them was very close to each other with no significant differences. So the $5 \%$ level could be the one that we should stop consuming any additional sage which is in agreement with previous literatures that recommended prebiotics intake by about 5-8g/day. Additionally, any excess consumption could results in intestinal discomfort due to gas distension (Clausen \& Mortensen, 1997).

\section{Conclusion}

Sage is very easy to be used to spice up your meals with its healthy eating resulting from its potent flavones. Our study demonstrated to be as fiber-rich diet provides prebiotics potential effects influencing the gut microbiota compositions. However, many manageable set of well-designed experiments models (in vitro and in vivo) are needed to fully understand the digestion and fermentation of such prebiotics sources and potential manipulation of the microbioma in the human host. Therefore, it is important to design studies that can demonstrate specific potential of sage as 


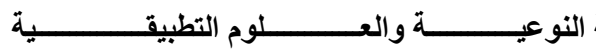

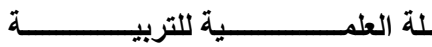

The Scientific Journal of Specific Education and Applied Sciences

dietary prebiotics sources examining the interactions between intestinal microbes and the gastrointestinal tract. Finally, new types of prebiotics or medicinal compounds derived from the microbiota may be used as future strategies to promote health, prevent disease, and treat different disorders.

\section{References}

Abu-Darwish, M.S.; Cabral, C. and Ferreira I.V., (2013). Essential oil of common sage (Salvia officinalis L.) from Jordan: assessment of safety in mammalian cells and its antifungal and anti-inflammatory potential. Biomed Res Int; 538940.

AIN. American Institute of Nutrition. (1993). Purified diet for laboratory Rodent, Final report J. Nutrition. 123:1939-1951.

Baillie, K. (2008). Clinic Long Article on Current Diabetes Trials. http://www.cliniclog .com /type 1 diabetes trials. Php.

Baricevic, D.; Sosa, S. and Della, L. (2001). Topical antiinflammatory activity of Salvia officinalis L. leaves: the relevance of ursolic acid. Jthnopharmacol ;75(2-3):125-32.

Byun, S.; Lee K.W. and Jung S.K. (2010). Luteolin inhibits protein kinase C (epsilon) and c-Src activities and UVB-induced skin cancer. Cancer Res. 15;70(6):2415-23.

Chapman, D.G.; Castilla, R. and champbell. J.A. (1959). Evaluation of Protein in food. I.A. Method for the determination of protein efficiency ration. Can. J. Biochemistry Physiology, 37: 679 - 686.

Clausen, M.R. and Mortensen PB. (1997). Lactulose, disaccharides and colonic flora. Drugs, 53, 930-42.

Davidson, M.H. and A. McDonald. (1998). Fiber: Forms and functions. Nutr. Res. 18:617-624.

Desai, A. C. and Bhide, M. B. (1985): Hypoglycemic activity of Hamiltonia suaveolens. Indian J. Med. Res. 81: 86-91. 


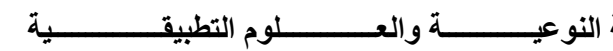
型

Dragana, M.; Branka, V.; Jelena K.; Stankovic, S. and Draga, S. (2005). Comparative study on the antibacterial activity of volatiles from sage (Salvia officinaliS 1.) Arch. Biol. Sci., Belgrade, 57 (3), 173-178.

Drasar.B.S. (1988). The bacterial flora of the intestine. In Rowland.I.R. (ed.). Role of the Gut Flora in Toxidty and Cancer. Academic Press, London, pp. 23-38.

Finegokl.S. M.; Attebery.H.R. and Surter.V.L. (1974). Effect of diet on human faecal flora: comparison of Japanese and American diet. Am. J. Din. Nutr., 27, 1456-1469.

Fossati, P. (1982). Serum triglycerides determined colorimetrically with an enzyme that produces hydrogen peroxide. Clinical Chemistry, 28: 2077.

Fredewaid, W.T. (1972). Determination of HDL. Clin. Chem., 18: 499.

Holdman.L.V., Good.,I.J. and Moore.W.E.C. (1976). Human fecal flora: variation in bacterial composition within individuals and a possible effect of emotional stress. AppL Environ. Microbiol., 31, 359-375.

Kennedy, D.O.; Pace, S.; Haskell, C., Okello, E.J.; Milne, A. and Scholey, A.B. (2006). Effects of cholinesterase inhibiting sage (Salvia officinalis) on mood, anxiety and performance on a psychological stressor battery. Neuropsychopharmacology. ;31(4):845-52.

Kianbakhta, S.and Dabaghian, F.H. (2013). Improved glycemic control and lipid profile in hyperlipidemic type 2 diabetic patients consuming Salvia officinalis L. leaf extract: A randomized placebo Controlled clinical trial. Compl Ther Med, 21(5):441-6.

Lee, R. and Nieman, D. (1996). Nutrition Assessment. $2^{\text {nd }}$ Ed., Mosby, Missouri, MI. 


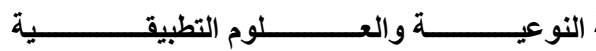
型

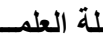

The Scientific Journal of Specific Education and Applied Sciences

López-Lázaro M. (2009). Distribution and biological activities of the flavonoid luteolin. Mini Rev Med Chem ;9(1):31-59.

Nazeha, A.; Gemma E.; Glenn R.; Kieran M. and Simon C. (2013). In vitro batch cultures of gut microbiota from healthy and ulcerative colitis (UC) subjects suggest that sulphatereducing bacteria levels are raised in UC and by a proteinrich diet. Int J Food Sci Nutr, 1-10.

Qnais, E.Y.; Abu-Dieyeh, M.; Abdulla, F.A. and Abdalla, S.S. (2010). The antinociceptive and anti-inflammatory effects of Salvia officinalis leaf aqueous and butanol extracts. Pharm Biol. ;48(10):1149-56.

Roberfroid, M.; Hoyles, L. and Mccartney, A. (2010). Prebiotic concept: definition, metabolic and health benefits. Br J Nutr, $104,1-63$.

Rother, K.I. (2007). Diabetes treatment -bridging the divide. The New England Journal of Medicine, 356 (15):1499-1501.

Sarbini, S; Kolida, S. and Deaville, E, (2014). Potential of novel dextran oligosaccharides as prebiotics for obesity management through in vitro experimentation. Br J Nutr, 112, 1303-14.

Scott, K.P.; Martin, J.C.; Duncan, S.H. and Flint, H.J. (2014). Prebiotic stimulation of human colonic butyrate-producing bacteria and bifidobacteria, in vitro. FEMS Microbiol Ecol, 87, 30-40.

Sutton, J. (2004). The Gardener's Guide to Growing Salvias. Workma Publishing Company. pp. 15-17. ISBN 978-088192-671-2.

Thomas, L. (1992). Labor and Diagnose, 4 th Ed. Mosby, Missouri, MI.

Tinder, p. (1969). Glucose, Ann. Clin. Biochem., (62): 24-33. 


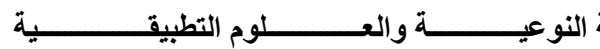
望

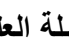

The Scientific Journal of Specific Education and Applied Sciences

Walker, J. B.; Sytsma, K. J.; Treutlein, J. and Wink, M. (2004). "Salvia (Lamiaceae) is not monophyletic: implications for the systematics, radiation, and ecological specializations of Salvia and tribe Mentheae". American Journal of Botany.91 (7): 1115-25. 